\title{
CML in India: Are We There Yet?
}

\author{
Uday Yanamandra $^{1} \cdot$ Pankaj Malhotra $^{2}(\mathbb{D}$
}

Received: 27 December 2018/ Accepted: 2 January 2019/Published online: 17 January 2019

(C) Indian Society of Hematology and Blood Transfusion 2019

The survival of patients with chronic myeloid leukemia (CML) has come close to healthy normal individuals with the advent of tyrosine kinase inhibitor (TKI), imatinib in the start of the millennium. The long-term overall survival (OS) of the patients recruited in the IRIS trial was $83.3 \%$ with no cumulative or late toxic effects of Imatinib after a median follow-up of 11 years [1]. Despite five other drugs approved by FDA in the management of the CML in the last two decades (Nilotinib, Dasatinib, Bosutinib, Ponatinib, and Omacetaxine), the OS in population-based studies is lower than reported in the trials. In this edition of the journal, Ganesan et al. [2] have published the long-term survival of CML patients from real-world settings in India. The authors reported 10y-OS close to $76 \%$ in the realworld settings, which is marginally less than the west but higher than that previously reported in our country [3].

The management of a treatable disease like CML is still fraught with five major hurdles in real-world scenario namely being different disease biology, patient education, access to therapy, appropriate PCR testing/disease monitoring, and adherence to treatment.

The median age of the patients in our country is a decade earlier than the west. A large percentage of patients belong to the third and fourth decade. This can severely impact the outcomes being economically productive age, different social/psychological needs and the challenges of

Pankaj Malhotra

hematpgi@gmail.com;

http://pgimer.edu.in

1 Department of Hematology and Stem Cell Transplant, Army Hospital (Research and Referral), New Delhi 110010, India

2 Department of Internal Medicine, PGIMER, Chandigarh 160012, India
TKI's impact on reproduction $[4,5]$. The disease biology in Indian patients may also be different owing to late presentation leading to greater high-risk patients, increased incidence of myelofibrosis, and increased number of accelerated/blast phase patients at diagnosis $[4,6]$. As was also elucidated by Ganesan et al. [2] the high-risk patients fare poorly than the low-risk patient. Patient's understanding of the disease and related therapeutic implications are essential for timely initiation of therapy and ensuring compliance which in turn is dependent on background educational level.

Access to therapy is a significant challenge in the lowand middle-income countries. Most of the patients were on the patient assistance program in the study under reference. Access to these assistance programs does not reflect the true outcomes in a real-world setting, as these patients are closely monitored akin to clinical trials. Patient assistance programs aid not only on the regular drug supply in patients with poor socio-economic status but also ensures the compliance which can significantly impact the survival as demonstrated in a study from north India [7].

Disease monitoring is a key for optimal outcomes through appropriate modification of the therapy. Lack of timely PCR testing in noted even in 15-20\% of the patients in the west with adequate facilities, the figure is much higher in the real-world settings. There is a lack of standardization of the available tests/labs as well as testing facilities across the country, high costs and non-availability of test on an international scale (IS) [8]. Timely testing also allows for assessing newer surrogate markers such as early achievement of complete hematological response within 6 weeks instead of 12 weeks (CHR velocity) and early molecular response [9].

Adherence to therapy is a crucial factor in dictating OS in a disease requiring lifelong TKI. Ganesan et al. [2] 
emphasized the relevance of adherence to treatment as the only indicative factor determining OS in this long-term retrospective cohort. In a real-world scenario, the adherence is dictated by several factors including availability of drugs, enrolment to the patient assistance program, distance from hospitals, socioeconomic status of the patient and the education level of the patient as was elaborated in detail from a previous study [7]. The adherence is also dictated by the side-effect profile of the TKI both perceived by treating physicians and the patients alike. Studies on the audiovestibular, secondary malignancies, mucocutaneous and obstetric side effects published from India did clear some myths about the overhyped Imatinib toxicity profile [5, 10-13].

In recent years, studies suggest stopping TKI in patients who were on long-term therapy with prolonged periods of deep molecular response. Stopping TKI in the real-world setting especially the generic imatinib should be analyzed in perspective of the above-discussed shortcomings particularly intensive testing following stoppage of the drugs [14]. Despite TKI being the most significant discovery of the millennium in the management of $\mathrm{CML}$, we require great strides before a quiet-introspection on "Are We There Yet?" in managing CML in real-world settings particularly India.

\section{Compliance with Ethical Standards}

Conflict of interest The authors declare that they have no conflict of interest.

Human and Animal Rights This article does not contain any studies with human participants performed by any of the authors.

\section{References}

1. Hochhaus A, Larson RA, Guilhot F, Radich JP, Branford S, Hughes TP et al (2017) Long-term outcomes of imatinib treatment for chronic myeloid leukemia. $N$ Engl $\mathrm{J}$ Med 376(10):917-927

2. Ganesan P, Ganesan TS, Radhakrishnan V, Sagar TG, Kannan K, Dhanushkodi $\mathrm{M}$ et al (2018) Chronic myeloid leukemia: longterm outcome data in the imatinib era. Indian J Hematol Blood Transfus. https://doi.org/10.1007/s12288-018-1009-y
3. Nair V, Sharma A, Kotwal J, Bhikshapathy M, Mishra DK, Das S et al (2014) Monitoring of response to therapy with imatinib mesylate in Chronic Myeloid Leukemia in chronic phase (CMLCP). Med J Armed Forces India 70(4):315-320

4. Yanamandra U, Sahu KK, Karunakaran $P$, Katoch D, Jain N, Khadwal A, Prakash G, Lad D, Naseem S, Varma N, Varma S, Malhotra P (2018) Adolescent and young adult chronic myeloid leukemia in real-world settings: experience from a tertiary care institute in northern India. J Adolesc Young Adult Oncol. https:// doi.org/10.1089/jayao.2018.0007

5. Rohilla M, Rai R, Yanamandra U, Chaudhary N, Malhotra P, Varma N et al (2016) obstetric complications and management in chronic myeloid leukemia. Indian J Hematol Blood Transfus 32(1):62-66

6. Tahlan A, Varma N, Naseem S, Bansal D, Binota J, Sood A et al (2018) Comparative study of clinico-hematological features, molecular spectrum and response to imatinib in chronic myelogenous leukemia patients: pediatric and adolescent versus adults. Indian J Hematol Blood Transfus 34(1):19-24

7. Yanamandra U, Malhotra P, Sahu KK, Sushma Y, Saini N, Chauhan P et al (2018) Variation in adherence measures to imatinib therapy. J Glob Oncol 4:1-10

8. Anand MS, Varma N, Varma S, Rana KS, Malhotra P (2012) Cytogenetic \& molecular analyses in adult chronic myelogenous leukaemia patients in north India. Indian J Med Res 135:42-48

9. Chikkodi SV, Malhotra P, Naseem S, Khadwal A, Prakash G, Sahu KK et al (2015) Factors affecting early molecular response in chronic myeloid leukemia. Clin Lymphoma Myeloma Leuk 15(Suppl):S114-S119

10. Gupta R, Yanamandra U, Gupta B, Panda NK, Varma S, Nagarkar A et al (2017) Audio vestibular status in CML patients on imatinib mesylate with review of literature. Indian J Hematol Blood Transfus 33(2):175-180

11. Vinay K, Yanamandra U, Dogra S, Handa S, Suri V, Kumari S et al (2018) Long-term mucocutaneous adverse effects of imatinib in Indian chronic myeloid leukemia patients. Int J Dermatol 57(3):332-338

12. Sahu KK, Dhibar DP, Varma S, Malhotra P (2017) CML with pregnancy: real challenges in developing nations. Leuk Lymphoma 58(6):1518-1519

13. Sahu KK, Uday Y, Bal A, Varma N, Naseem S, Khadwal A et al (2016) CML as part of dual malignancies - a retrospective analysis: possible mechanisms and review of literature. Indian $\mathbf{J}$ Hematol Blood Transfus 32(4):392-396

14. Goni D, Jindal N, Mishra K, Jain A, Lad D, Naseem S et al (2018) Treatment free remission with generic imatinib. Indian J Hematol Blood Transf Suppl 1:298

Publisher's Note Springer Nature remains neutral with regard to jurisdictional claims in published maps and institutional affiliations. 